complement 'outline courses' in medieval and modern history of the Faculty of History. The films shown included "Alexander Nevsky", "Der Alte und Junge König" and "M. Vincent". In collaboration with the same Association the Film Council also arranged a film demonstration at which the films "Stone Age Tools", "Paridiso Perduto", "Transfer of Power", and "Edwardian Newsreel" were shown. Film sessions have also been arranged for students of economics, Slavonic studies, archæology, anthropology, geography, engineering and zoology. Considerable use of films is made in the Department of Anatomy, where films for teaching purposes have been made. A useful teaching film showing stream erosion in a laboratory model has been completed in the Department of Geography. The use of cinematography in research continues in a number of university departments, including those of engineering, geography, geodesy and geophysics, and experimental psychology. In the Department of Anatomy, films showing the growth of nerve fibres and the reaction of chemotherapeutic compounds on living cells have been made; in the Cavendish Laboratory a new version of the bubble model film has been prepared.

\section{Three-Dimensional Films}

$I_{T}$ is curious that the widespread interest in three-dimensional films should have been stimulated by the appearance of a two-dimensional panoramic system--'Cinerama'--followed closely by the announcement of a similar system yet to come-

'Cinemascope'. Although both are spectacular, neither method is truly stereoscopic, the specious illusion of some depth attained being dependent upon wide-angle peripheral vision and upon the slightly different images seen by each eye, both effects being conferred by a curved screen. Other older systems which rely upon a truly three-dimensional presentation have benefited by this publicity in being brought more into public awareness. Before a film can be called ' $3-D$ ' it must be truly stereoscopic. For this, it is essential that each of the viewing eyes shall receive a dissimilar picture from the other-the so-called 'disparate' images that are seen in real life by two separated eyes. In consequence, whatever the methods of projecting pictures upon the screen may be, it is essential that there should be differentiation as between the two eyes, either at the eyes or at the screen. Systems using the first of these methods, where the required discrimination takes place at the eyes, are at the moment more successful and are commercially therefore more important. The possibilities of three-dimensional films are discussed by H. Dewhirst in a recent issue of Science and Film.

\section{Limits of the Oceans and Seas}

THE third edition of "Limits of Oceans and Seas" has been published by the International Hydrographic Bureau, Monte Carlo (pp. 38 ; 1953 ; n.p.), and consists of thirty-eight pages of text and three large diagrams, giving the position and extent of the seas. The limits as described in the text and shown in the diagrams are solely for the convenience of national hydrographic offices in compiling notices to mariners and for other practical reasons ; they have no relation to physical considerations and, of course, are of no political significance. The Antarctic, or Southern Ocean, is now omitted on the plea that this body of water has no well-defined limits to the north, but rather a seasonal variation. The southern limits of the other oceans are therefore extended to the Antarctic continent, and the various Antarctic seas, such as Ross, Weddell and Bellingshausen, are omitted. Straits joining two seas have been allotted to one of them. Meridians, parallels and rhumb lines have been used so far as possible for the limits of seas. The extent of the great oceans, including the Arctic Ocean, excludes the seas lying within each of them, this being mainly for practical purposes.

\section{Men of the Trees}

ThE summer issue of the journal of the Society of the Men of the 'Trees contains an account by Mr. Richard St. Barbe Baker of the expedition which he led last year to survey desert areas in Africa and to advise on means of combating erosion by afforestation (17, No. 1). To publicize and finance the "green front campaign against the desert", stamps have been produced showing a 'lone tree' in the middle of the Sahara. This tree stands six hundred miles from others in the middle of the desert, although the forest which was once there had disappeared because of drought or had been obliterated by sand storms. With the money collected from the sale of the stamps it is hoped to complete the desert survey and to purchase tree seeds and start tree nurseries in positions where they are most urgently needed. The journal also contains articles on the New Forest by J. Brambell Hill, the Worcester Beacon by E. R. Gordon, Cranford Park by A. Leonard Summers, the third in a series of articles on the biological task of forestry by Henry Baldwin, and a fine lyrical poem on elms by Leonora Lockhart.

\section{Mutagenic Possibilities of Phosphorus-32}

THE occurrence and utility of bud sports in fruit trees have been discussed by W. R. Stanton and W. K. Sinclair (J. Exp. Bot., 4, 10, $78 ; 1953$ ) and the merits of various mutagenic agents compared. These authors suggest that phosphorus-32 may prove a suitable mutagen in the production of fruit-tree mutations. In particular, experiments are described on the uptake and distribution of phosphorus-32 by plums. It is shown that the concentration of phosphorus-32 in buds may reach a level at which mutagenic effects are likely to be induced, but that at such concentrations there is little evidence of macroscopic injury. The method which is described - based on the culture of young trees in sand plus nutrients-appears to be suitable for fruit trees.

Micro-organisms maintained in Australian Institutes

THE Commonwealth Scientific and Industrial Research Organization of Australia has issued a booklet entitled "Directory and Catalogue of Microorganisms maintained in Australia", which lists the micro-organisms held as type cultures in the biological institutes of Australia (pp. 74; Melbourne: C.S.I.R.O., 1952). This work has been done to implement a recommendation of the British Commonwealth specialist conference on culture collections of micro-organisms, which was held in London during August 1947, that a directory of important culture collections in the Commonwealth should be prepared. At present there is no centralized collection in Australia. The Australian "Directory" embodies infor mation submitted by forty-two institutions and lists several hundred species of bacteria and fungi, some seven species of protozoa, some fifty strains of yeasts, fifty-seven strains of bacteriophages, and twentynine strains of viruses. The strains are classified into 